\title{
laborhifórico
}

ISSN 2359-6910

https://revistas.ufrj.br/index.php/lh/

FONTES PRIMÁRIAS

Recebido em 20 de janeiro de 2021

Aprovado em 10 de março de 2021

\section{Cartas Jesuíticas: solicitação de promoção escrita por Joseph Maria Cabrer a Antonio Samper}

DOI: https://doi.org/10.24206/lh.v7i2.40946

Vanessa de Azevedo Baeta Alves Pereira

Graduada em Letras Português/ Espanhol (UFRJ), Mestre e Doutoranda em Letras Neolatinas (UFRJ).

E-mail: vanessabaeta1984@gmail.com ORCID: http://orcid.org/0000-0002-9063-9486 


\section{RESUMO}

O presente texto tem por base o meu anteprojeto de doutorado que tem o objetivo de se debruçar sobre a coleção de manuscritos pertencentes à Biblioteca Nacional do Rio de Janeiro intitulada Coleção Pedro de Angelis. Apresentamos aqui um dos documentos da coleção referenciada anteriormente que possui a seguinte temática: Carta de felicitação de Joseph Maria Cabrer a Antonio Samper pelo novo posto de Chefe do Estado Maior do Real Corpo de Engenheiros. O documento em questão, escrito em 1803, trata da felicitação e dá diversas notícias, como as expedições de demarcação de limites territoriais entre as coroas de Espanha e Portugal. O autor reconhece rios, paisagens e aberturas de caminhos relatando seu oficio como engenheiro e tenente-coronel. O documento contém ainda, em consideração às tarefas executadas em seu cargo, o pedido de reconhecimento de mérito e promoção para um cargo superior, de sargento maior da Praça de Buenos Aires.

Palavras-chave: Coleção Pedro de Angelis. Biblioteca Nacional do Rio de Janeiro. Expedições. Fronteiras. Buenos Aires. 


\section{Introdução}

De acordo com Schell (2014), Pedro de Angelis (Nápoles, 1784 - Buenos Aires, 1859) era italiano, porém se naturalizou argentino. Foi um historiador em sua época e também exerceu diversas outras funções, dentre elas a de professor de geografia, bibliotecário, jornalista e militar, lutando nas guerras napoleônicas.

Pedro de Angelis, além das diversas ocupações que desempenhou, também dedicou-se a organizar arquivos de documentos ligados à história, à geografia e aos povos nativos da Argentina, tornando-se um importante detentor de documentos, tanto contemporâneos quanto anteriores a sua época, que continham informações importantes acerca da história colonial e pós-independentista do Rio da Prata, Patagônia, Bolívia, Estreito de Magalhães, missões jesuíticas, línguas indígenas, litoral, rios e fronteiras da América do Sul.

Entre 1837 e 1853 ocorreu a negociação da compra da coleção de Angelis por D. Pedro II, então imperador do Brasil. A coleção adquirida e composta por assuntos que versavam sobre Jesuítas; Fronteiras; Companhia de Jesus; Missões; Índios da América do Sul; Índios Mojo; Rios da América do Sul, entre outros, foi comprada pelo valor de 8 mil pesos e compreendia 2.785 livros impressos e 1.291 documentos e mapas, totalizando 4.076 peças das quais hoje podemos encontrar uma parte no acervo da Fundação Biblioteca Nacional.

Apesar de grande parte do acervo coletado por Pedro de Angelis encontrar-se no Brasil, no Ministério das Relações Exteriores e na Biblioteca Nacional do Rio de Janeiro, outros documentos se encontram também em bibliotecas públicas e privadas da Argentina e no Archivo General de la Nación.

A coleção de Angelis, pertencente à Biblioteca Nacional do Rio de Janeiro, encontra-se parcialmente microfilmada e digitalizada. São documentos em espanhol, muitos deles produzidos na América. Há um total de 1210 registros na BN Digital e, em grande parte, feitos a partir de microfilmes.

Ainda sobre a divulgação dos textos, uma parte da coleção foi transcrita pelo historiador Jaime Cortesão, entre os anos de 1951 a 1969, e está disponível online (http://bndigital.bn.br/projetos/angelis/exposicao2.html). Trata-se da coleção intitulada Manuscritos da Coleção de Angelis, que conta com 7 volumes com introdução, notas e glossário.

O documento selecionado para este artigo, Cartas Jesuíticas: solicitação de promoção escrita por Joseph Maria Cabrer a Antonio Samper, foi escrito em Buenos Aires, possui data de 18 de agosto de 1803 e é um manuscrito do gênero carta que trata da felicitação de Joseph Maria Cabrer a Antonio Samper pelo novo posto de Chefe do Estado Maior do Real Corpo de Engenheiros. Além das 
felicitações, diversas notícias são dadas, como as expedições de demarcação de limites territoriais entre as coroas de Espanha e Portugal, o reconhecimento de rios e paisagens, a abertura de caminhos e o seu oficio como engenheiro e tenente-coronel. Por fim, levando-se em consideração as tarefas executadas em seu cargo, o autor pede reconhecimento de mérito por seu trabalho e consequente promoção para um cargo superior, de sargento maior da Praça de Buenos Aires.

Cabe ressaltar que o título Carta jesuítica, atribuído primeiramente para este documento manuscrito, não contempla a especificidade do conteúdo apresentado. Diante deste impasse, para fins de apresentação deste trabalho, foi acrescentado ao título existente um título sugerido a partir de uma análise minuciosa do conteúdo apresentado no documento afim de complementar o título original que precisa ser revisto.

Como objeto de análise e estudo filológico proposto em anteprojeto de doutorado, a partir da coleção Pedro de Angelis, foi selecionado para este texto o documento em questão pertencente à seç̧ão de manuscritos da Biblioteca Nacional do Rio de Janeiro para fins de execução de uma edição semidiplomática cujas normas de edição apresento a seguir.

\section{Normas de transcrição}

A edição que se apresentará neste artigo será semidiplomática. Adotará uma natureza mais conservadora, na qual serão respeitadas todas as particularidades do manuscrito, como grafia, maiúsculas e minúsculas, pontuação, acentuação, paragrafação, divisão de linhas etc. A única intervenção realizada se refere ao desenvolvimento de abreviaturas, nas quais serão destacadas, em itálico, as letras ou sequências inseridas. 


\section{Fac-símiles}

[fol. 1r]

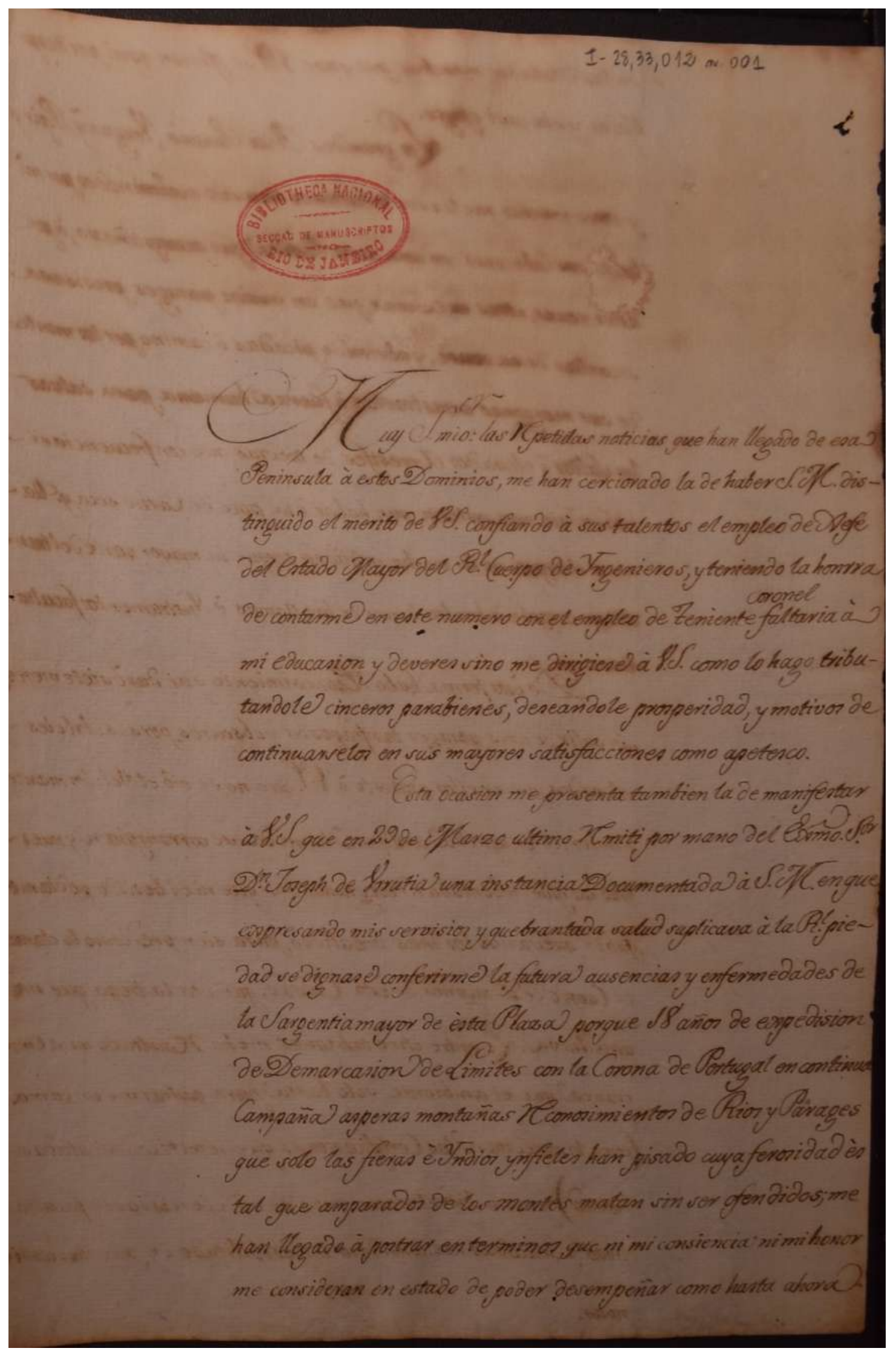


[fol. 1v]

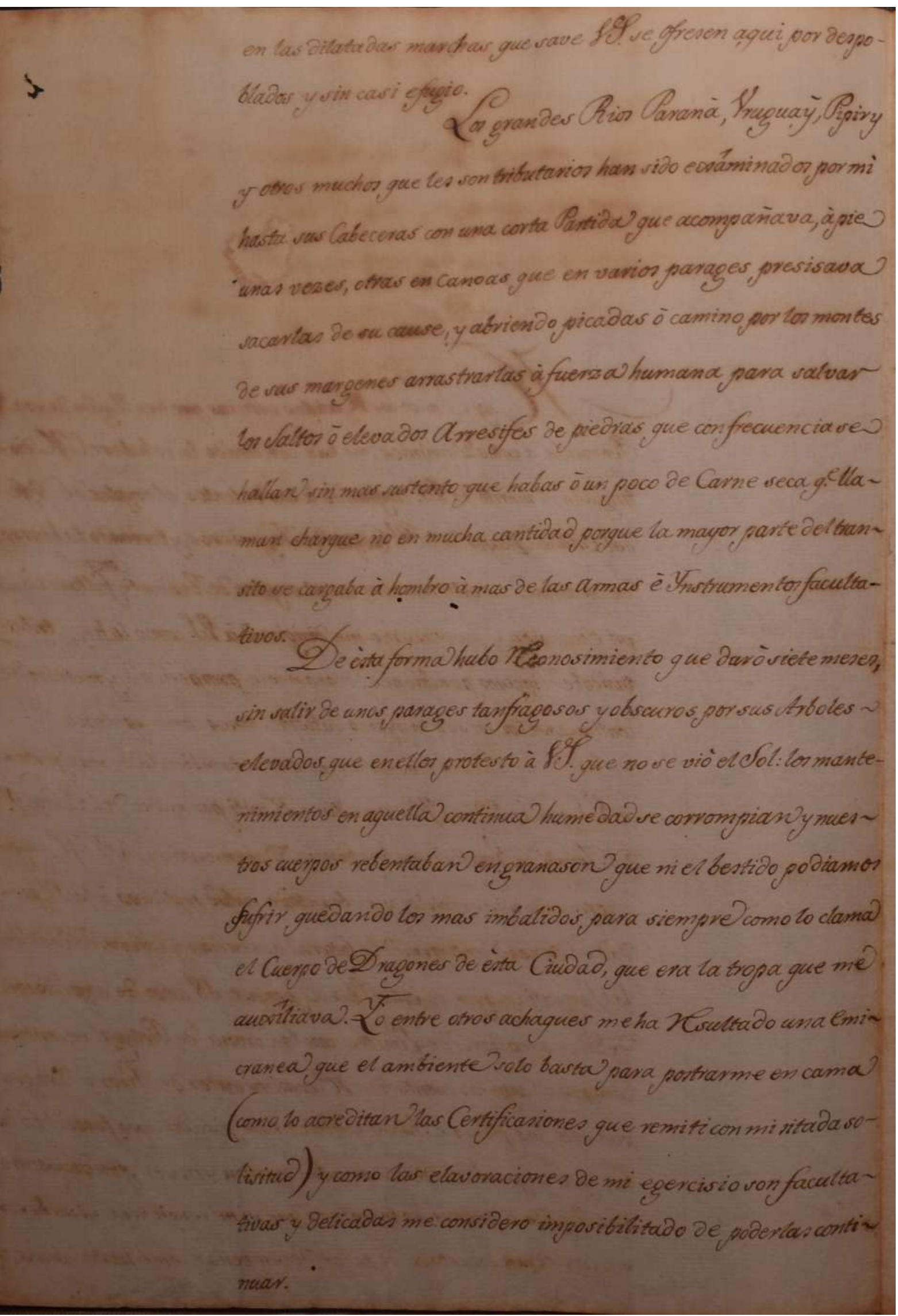


[fol. 2r]

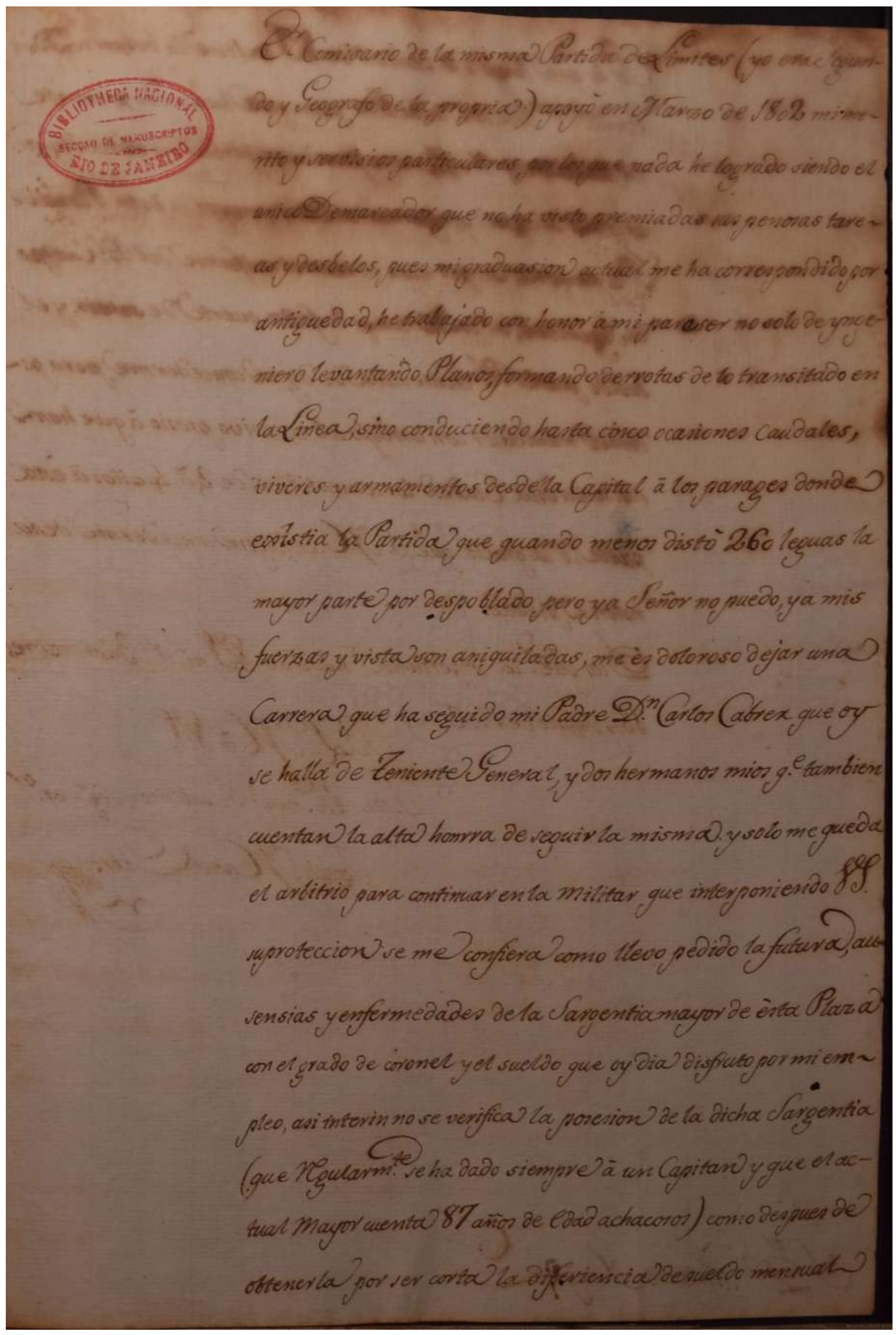


[fol. 2v]

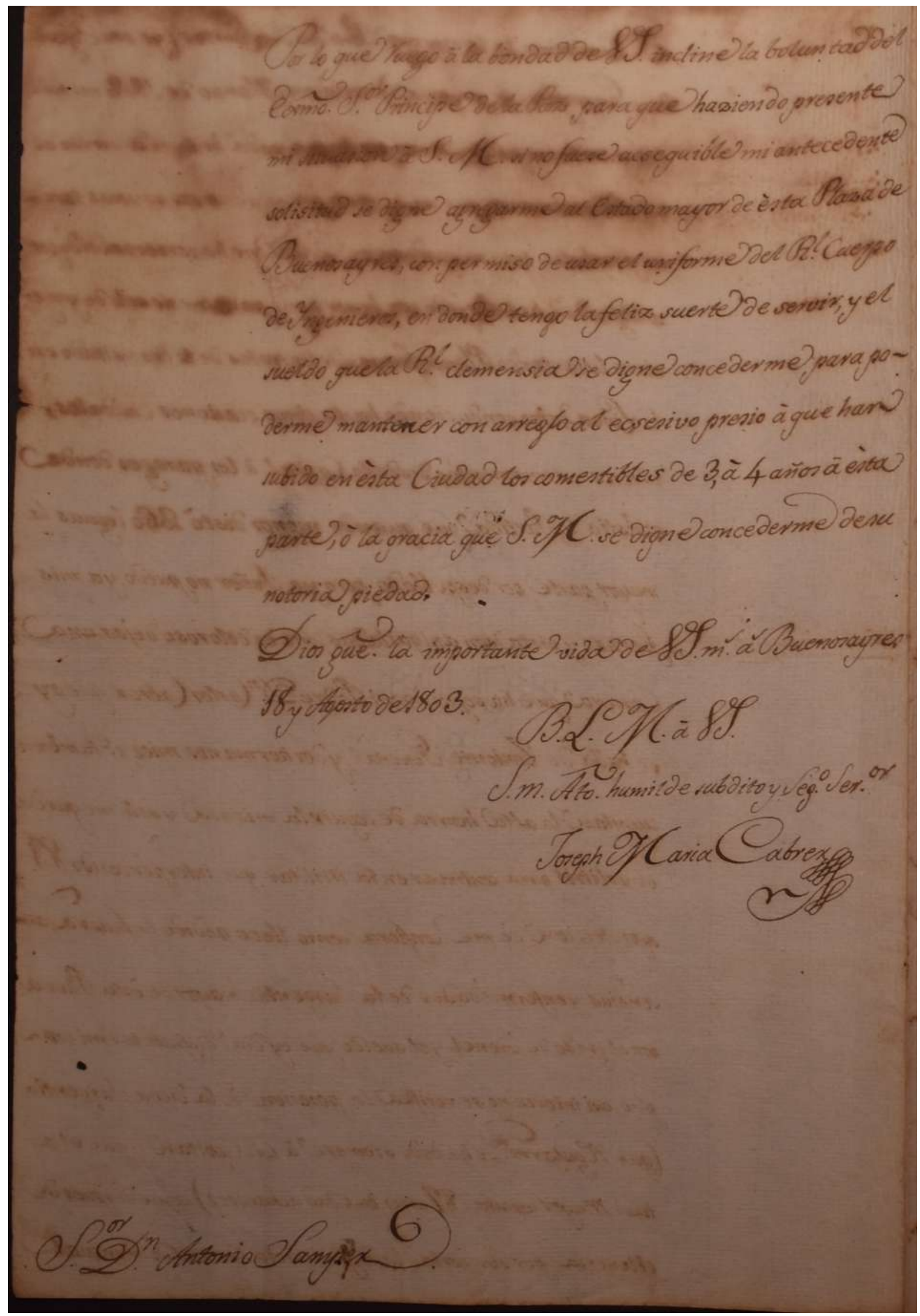




\section{Transcrição}

Documento I-28,33,12 n. 01

Cartas jesuíticas

Buenos Aires 18/08/1903

$4 \mathrm{P}$

Coleção de Angelis

MS 508 (44)

[fol. 1r]

Muy Señor mio: las repetidas noticias que han llegado de esa Península à estos Dominios, me han cerciorado la de haber $\mathrm{S} u$ Magestad distinguido el merito de Vuestra Señoría confiando à sus talentos el empleo de Jefe del estado Mayor del Real Cuerpo de Yngenieros, y teniendo la honrra de contarme en este numero con el empleo de Teniente [coronel] faltaría à mi educación y deveres sino me dirigiese à Vuestra Señoría como lo hago tributandole sinceros parabienes, deseandole prosperidad, y motivos de continuarselos en sus mayores satisfacciones como apetesco.

Esta ocasión me presenta también la de manifestar à Vuestra Señoría que en 29 de Marzo ultimo remiti por mano del Excelentísimo Señor Don Joseph de Vrrutia una instancia Documentada à Su Magestad. en que expresando mis servisios y quebrantada salud suplicava à la Real piedad se dignase conferirme la futura ausencias y enfermedades de la Sargentia mayor de èsta Plaza porque 18 años de expedision de Demarcasion de Limites con la corona de Portugal en continua campaña asperas montañas reconocimientos de Rios y Parages que solo las fieras è indios ynfieles han pisado cuya ferosidad ès tal que amparados de los montes matan sin ser ofendidos; me han llegado à postrar en terminos que ni mi conciencia ni mi honor me consideran en estado de poder desempañar como hasta ahora 
[fol. 1v]

en las dilatadas marchas que sabe Vuestra Señoría se ofrecen aqui por despoblados y sin casi efugio.

Los grandes Rios Paraná, Vruguay, Pipiry y otros muchos que les son tributarios han sido examinados por mì hasta sus Cabeceras con una corta Partida que acompañava, à pie unas vezes, otras en canoas que varios parages precisava sacarlas de su cause, y abriendo picadas ò camino por los montes de sus margenes arrastrarlas à fuerza humana para salvarlos saltos ò elevados arresifes de piedras que con frecuencia se hallan sin mas sustento que habas ò un poco de carne seca que llaman charque no en mucha cantidad porque la mayor parte del transito se cargaba à hombro à mas de las armas è Ynstrumentos facultativos.

De èsta forma hubo reconosimiento que dar ò siete meses, sin salir de unos parages tan fragosos y obscuros por sus Arboleselevados que en ellos protesto à Vuestra Señoría que no se viò el Sol: los mantenimientos en aquella continua humedad se corrompian y nuestros cuerpos rebentaban en granason que ni el bestido podíamos sufrir quedando los más inválidos para siempre como lo clama el Cuerpo de Dragones de èsta Ciudad, que era la tropa que me auxiliava. Yo entre otros achaques me ha resultado una emicranea que el ambiente solo basta para postrarme en cama (como lo acreditan las Certificasiones que remiti con mi sitada solicitud) y como las elavoraciones de mi egercisio son facultativas y delicadas me considero imposibilitado de poderlas continuar. 
[fol. 2r]

El Comisario de la misma Partida de Limites (yo era Segundo y Geografo de la propria) apoyò en Marzo de 1802 mi merito y servisios particulares por los que nada he logrado siendo el unico Demarcador que no ha visto premiadas sus penosas tareas y desbelos, pues mi graduasion actual me ha correspondido por antiguedad, he trabajado con honor à mi para ser no solo de yngeniero levantando Planos, formando derrotas de lo transitado en la Linea, sino conduciendo hasta cinco ocasiones caudales, viveres y armamentos desde la Capital à los parages donde existia la Partida que quando menos distò 260 leguas la mayor parte por despoblado pero ya Señor no puedo, ya mis fuerzas y vista son aniquiladas, me ès doloroso dejar una Carrera que ha seguido mi Padre Don Carlos Cabrer que hoy se halla de Teniente General, y dos hermanos míos que también cuentan la alta honrra de seguir la misma y solo me queda el arbitrio para continuar en la militar que interponiendo Vuestra Señoría su protección se me confiera como llevo pedido la futura, ausensias y enfermedades de la Sargentia mayor de èsta Plaza con el grado de coronel y el sueldo que hoy dia disfruto por mi empleo, asi interin no se verifica la posesion de la dicha Sargentia (que regularmente se ha dado siempre à un Capitan y que el actual Mayor cuenta 87 años de edad achacosos) como después de obtenerla por ser corta la diferiencia de sueldo mensual 
$[\mathrm{fol} .2 \mathrm{v}]$

Por lo que ruego à la bondad de Vuestra Señoria incline la voluntad del Exelentísimo Señor Príncipe de la Paz para que haziendo presente mi situasion à $\mathrm{S} u$ Magestad si no fuese acsequible mi antecedente solicitud se digne agregarme al estado mayor de èsta Plaza de Buenos aires, con permiso de usar el uniforme del Real Cuerpo de Yngenieros, en donde tengo la feliz suerte de servir, y el sueldo que la Real clemencia se digne concederme para poderme mantener con arreglo al ecsesivo presio à que han subido en èsta Ciudad los comestibles de 3, à 4 años à esta parte, ò la gracia que $\mathrm{S} u$ Magestad se digne concederme de su notoria piedad.

Dios guarde la importante vida de Vuestra Señoría muchos años Buenos aires 18 y Agosto de 1803.

\section{Beso Las Mano à Vuestra Señoria}

$\mathrm{S} u$ Magestad Atento humilde subdito y Seguro Servidor Joseph Maria Cabrer

Señor Don Antonio Samper 


\section{Referências bibliográficas}

ACIOLI, V. L. C. A Escrita no Brasil Colônia: um guia para leitura de documentos manuscritos. Recife: Editora Universitária UFPE/Fundação Joaquim Nabuco/Ed. Massangana, 1994.

AZEVEDO FILHO, Leodegário Amarante de. Iniciação em crítica textual. Rio de Janeiro: Presença; São Paulo: Edusp, 1987.

BLECUA, A. Manual de Crítica Textual. Madrid: Castalia, 1983.

CAMBRAIA, C. N. Introdução à crítica textual. São Paulo: Martins Fontes, 2005.

SCHELL, D. C. Colecionando documentos, escrevendo história, imaginando uma nação: Pedro de Angelis e sua operação historiográfica na "Colección de obras y documentos relativos a la historia antigua y moderna de las provincias del Río de la Plata”. Anais do XI Encontro Internacional da ANPHLAC. Niterói, 2014.

SCHELL, D. C. Entre coleções e arquivos: Pedro de Angelis e a produção de conjuntos documentais (Buenos Aires, 1835-1852). Tese (Doutorado em História) - Faculdade de História, Universidade Federal do Rio Grande do Sul. Porto Alegre, 2018. 